\title{
HORTA ESCOLAR: UMA ALTERNATIVA DE EDUCAÇÃO AMBIENTAL, ALCÂNTARA (MA)
}

\author{
Celso de Almeida Ramos ${ }^{1}$ \\ Lorran André Moraes ${ }^{2}$ \\ Leilson Alves dos Santos ${ }^{3}$ \\ Maria de Fátima Veras ${ }^{4}$
}

Resumo: O crescente desenvolvimento do consumismo e a exploração dos recursos naturais têm aumentado significativamente e, como consequência, a necessidade de formar indivíduos cada vez mais conscientes a respeito da preservação dos recursos naturais tem se tornado um imperativo na atualidade. Dessa forma, as questões ambientais vêm ganhando cada vez mais ênfase. A pesquisa traz como proposta um projeto de intervenção escolar como forma de promover a conscientização ambiental de alunos do Centro de Ensino em Tempo Integral Aquiles Batista Vieira, da cidade de Alcântara, no Maranhão, através da execução da disciplina eletiva intitulada: "Educação Ambiental na Horta Escolar". Por meio desta disciplina, foi implantada uma horta escolar pelos próprios alunos, os quais puderam associar a prática à teoria e por fim apresentarem $\circ$ que aprenderam durante o curso, por meio de uma culminância do projeto. Essa experiência trouxe aos educandos uma maior contextualização dos conhecimentos teóricos abordados em sala de aula e mostrou a horta escolar não só como uma simples forma de cultivo de hortaliças, mas também como um laboratório de aprendizagem de conhecimentos tão específicos que simples aulas teóricas não seriam capazes de promover.

Palavras-chave: Alcântara (MA); Educação Ambiental; Ensino; Práticas Diferenciais.

2 Mestrando em Biodiversidade, Meio Ambiente e Saúde - (CESC/UEMA). E-mail: lorranbio@hotmail.com

${ }^{3}$ Dep. Geografia e História na Universidade Estadual do Maranhão. E-mail: leylson.santos@gmail.com

${ }^{4}$ Universidade Estadual do Piauí - UESPI. E-mail: maria.fveras2018@gmail.com 


\section{Introdução}

Os impactos ambientais estão diretamente ligados ao aumento da população mundial e o consequente consumismo, que suscita cada vez mais a exploração de recursos naturais. Assim, é necessário formar indivíduos conscientes do seu papel na conservação da natureza (MINC, 2005). Tal inquietação está relacionada não só com o lado econômico, mas também com a questão de sobrevivência da humanidade.

Para Minc (2005), o homem interfere nas cadeias alimentares extinguindo espécies por meio da caça predatória e da degradação ambiental. A gravidade dos problemas ambientais pressupõe que as medidas para diminuir os impactos ambientais negativos na natureza e na sociedade devem ser tão prementes quanto o avanço da degradação do meio ambiente. Os valores difundidos na sociedade do consumo estimulam a extração de matériaprima da natureza, com o hábito de descartar em lixões a céu aberto, caracterizando uma relação depredatória na natureza (FOLADORI, 2010).

Com isso, as questões ambientais vêm ganhando cada vez mais relevo, tanto que Minc (2005) afirma que os assuntos relacionados à Ecologia já estão banalizados e tal aspecto ocorre em virtude da necessidade de mudanças em relação à degradação do ambiente, pois de acordo com o mesmo autor, a interferência humana é extremamente nociva à qualidade ambiental.

Diversos teóricos como Foladori (2010), Quintana e Hacon (2011) e Simonetti (2011) apontam os modos de produção e estilo de vida capitalista dominante como grandes responsáveis pelos impactos ambientais crescentes. Esses autores afirmam que tudo isso seria fruto de um sistema capitalista centrado no consumismo excessivo e isso acaba gerando uma visão utilitarista do ambiente. Chiavenato (2005) corrobora este pensamento quando afirma que essa realidade capitalista afeta a totalidade da biosfera.

Diante desta problemática, o objetivo de capacitar o intelecto das atuais gerações deve ser pautado no princípio de que a Educação Ambiental, segundo Medeiros et. al. (2011), pode abrir os olhos do educando para a realidade que o cerca, pois a problemática ambiental torna-se atualmente, cada vez mais frequente e necessária para o bom desenvolvimento do homem como um cidadão atuante e competente. Nessa perspectiva, a presente pesquisa traz como proposta, promover a conscientização ambiental de alunos da escola do Ensino Médio, denominada Centro de Ensino em Tempo Integral Aquiles Batista Vieira, da cidade de Alcântara, Maranhão, através da execução de uma disciplina eletiva intitulada: Educação Ambiental na Horta Escolar.

Essa disciplina visou construir e utilizar a horta escolar para estimular A aprendizagem de diversos temas relacionados à temática ambiental. Foram trabalhados em sala de aula teórica e paralelamente por meio de práticas em horários definidos, os conceitos ou ideias abordadas na teoria que puderam ser aplicados através da contínua construção da mini-horta pelos próprios educandos.

revista brasileira educação ambiental 
Essa forma de abordagem pedagógica é interessante, pois diversos trabalhos como de Costa, Souza e Pereira (2015); Pimenta e Rodrigues (2011); Borba, Vargas e Wizniewsky (2012) apontam a relevante importância da horta escolar como aplicação de um projeto de educação Ambiental, oportunizando um aprendizado contextualizado às demandas sociais atuais, a obtenção de bons hábitos alimentares e de consumo diário pelos alunos e a reutilização de materiais.

Esse tipo de intervenção leva em consideração que a escola como local de difusão de valores e comportamentos, deve viabilizar uma nova ética distinta daquela defendida pela sociedade do consumo. Tal intento pode ser alcançado por meio da sensibilização dos alunos sobre o meio ambiente, através da educação ambiental, visando educá-los para que levem experiências para a sua vida profissional e cotidiana. Esta mesma forma de educar, os Parâmetros Curriculares Nacionais (PCN's) estabelecem como um tema transversal a ser trabalhado com os alunos do ensino básico.

\section{Objetivos}

\section{Geral}

- Promover educação ambiental utilizando a horta escolar para promover práticas voltadas ao desenvolvimento sustentável.

\section{Específicos}

- Desenvolver o projeto da horta escolar como produto da teoria vivida em sala de aula;

- Aplicar a técnica de compostagem como forma de promover uma destinação mais adequada para o lixo orgânico da escola, evitando o desperdício;

- Exemplificar práticas ambientais que podem ser incorporadas ao cotidiano.

\section{Referencial Teórico}

\section{Ensino de biologia}

Ensinar nos dias atuais é algo que tem se tornado cada vez mais desafiador. Não é de se admirar que educadores como Mello (1996) e (2001), caracterizam a educação como um elemento primordial para o avanço de uma sociedade ou de um povo. Cada componente curricular que o processo educativo possa proporcionar aos educandos é de extrema importância. Um desses componentes é a Biologia, que apresenta grandes desafios de inserção do educando no mundo de conteúdo diversificado e extenso.

Sobre este assunto, Nunes Moura (2011), diz que o ensino de Biologia 
metodologia têm sido direcionados no preparo de estudantes para prestar exames de vestibulares, distanciando-se da amplitude do conhecimento biológico contextualizado. Diante disto, pode-se perceber que o desafio de situar os educandos num contexto em que a aprendizagem da disciplina de Biologia possa ser mais ligada ao seu cotidiano é um imperativo cada vez mais evidente.

Isso é um fato tão real, que os PCN's deixam bem explícita essa necessidade de contextualizar a Biologia com as questões da atualidade do educando, quando diz que elementos da história e da filosofia da Biologia tornam possível aos alunos a compreensão de que há uma ampla rede de relações entre a produção científica e o contexto social, econômico e político (BRASIL, 1997). No mesmo documento ainda se comenta que muitos conceitos importantes dentro dessa área trazem para os educandos, aspectos éticos envolvidos na produção e aplicação do conhecimento científico e tecnológico, chamando à reflexão as relações entre a ciência, a tecnologia e a sociedade.

\section{Educação ambiental}

Piaget (1967) discorre que o ser humano desde os anos iniciais do processo de ensino, aprendizagem e assimilação do mundo a sua volta, já precisa realizar constantemente associações cognitivas ou inter-relações do que os sentidos se apropriam, com a ideia racional ou inteligível resultante dessas interações com o mundo em sua volta. É por meio da percepção que a imaginação acontece e o indivíduo estrutura sua representação cognitiva do ambiente. Um dos meios que promovem uma boa associação dos sentidos com a inteligibilidade de determinados conteúdos educacionais é o lúdico.

O lúdico promove sentimentos de liberdade e espontaneidade de ação, ou seja, infalivelmente traz a atmosfera de conforto e diversão (ALMEIDA, 2003). Diante disto, não há como se pensar no corpo sem se pensar no lúdico, assim como não há como se pensar lúdico sem se pensar corpo.

Partindo-se desse pressuposto, o espaço da escola pode favorecer essa redescoberta do corpo em harmonia com o ambiente. Em classes de Educação de Jovens e Adultos (EJA), por exemplo, há muitos recursos que podem ser utilizados para retomar questões do meio ambiente a partir da própria experiência de vida de cada aluno. A horta pode ser um desses recursos.

Para participar ativamente de processos de conservação/restauração do ambiente natural e da valorização/resgate das culturas tradicionais/sustentáveis, os indivíduos necessitam ter uma consciência corporal/ambiental despertada, para que possam, além de entender conceitos, discutir e construir valores. Por isso, é preciso sensibilizar pela construção e pela manipulação de materiais com as mãos, pelos movimentos do corpo e pelo despertar das sensações (ALMEIDA, 2003). 
Essas estratégias de ensino ajudam a entender ou praticar uma forma mais adequada no ensino da Educação Ambiental, pois envolve a ideia de que tudo o que se consome desequilibradamente pode acarretar escassez futura e entender que, 0 que se utiliza pode resultar em impactos ambientais posteriores. Nos dias presentes são características indissociáveis de indivíduos comprometidos com os ideais e valores que pregam o preservacionismo dos recursos naturais.

Silva (2012) relata que, quando se cultiva o senso de preservação desde os anos iniciais do processo de educação, contribui-se para a formação de indivíduos colaboradores do Meio Ambiente, no sentido de que, durante o seu processo de formação escolar, ele teve a oportunidade de desenvolver-se como cidadão consciente de suas atitudes e das consequências que elas possam trazer à natureza, inclusive o consumismo, quando este é um fator compulsivo e impensado. Em seu enfoque, a Educação Ambiental deve buscar uma perspectiva de ação holística que relaciona o homem, a natureza e 0 universo, tendo como referência o esgotamento dos recursos naturais, cujo principal responsável pela sua degradação é o ser humano (JACOBI, 2003).

Não apenas visando a essa ideia de preservacionismo, mas tendo a visão do todo, a Educação Ambiental pode desenvolver outras habilidades e valores que constroem a identidade do cidadão de bem. A educação ambiental não deve apenas preocupar-se com a aquisição de conhecimentos científicos ou com campanhas utópicas de proteção ao meio ambiente (QUADROS, 2007). Devido às suas características multidimensionais e interdisciplinares, se aproxima e interage com outras dimensões da educação contemporânea, tais como a educação para os direitos humanos, para a paz, para a saúde, para o desenvolvimento e para a cidadania (BRASIL, 2007).

\section{Hortas escolares: do discurso à prática}

O resgate do vínculo do alimento com a natureza é central para o desenvolvimento de ações educativas na área de alimentação e nutrição. Nesse sentido, hortas escolares podem ser uma importante estratégia pedagógica, contando com um aprendizado baseado no contato direto com o alimento e a natureza (COELHO; BÓGUS, 2016). Sobre esta temática, Santana et. al. (2014), apresentaram resultados de uma intervenção pedagógica que se utilizava da horta escolar, acerca da possibilidade de trabalho prático sobre o tema Alimentação saudável, onde os educandos tornaram-se mais receptivos ao tema ministrado. Além de trazer essa ideia de educação alimentar, Eno, Luna e Lima (2015) destacam que o uso da horta escolar também é um meio de sensibilização coletiva de educação Ambiental. Como prática multidisciplinar, Pinheiro, Paula e Pessoa (2016) utilizaram a construção de horta escolar e puderam possibilitar a vivência de práticas transdisciplinares e reduzir a quantidade de resíduos sólidos no ambiente.

Diversos autores corroboram a importância de se construir hortas 
preservação do Meio Ambiente, como: Pimenta e Rodrigues (2011) Projeto Horta Escolar: Ações de Educação Ambiental na escola Centro Promocional todos os Santos de Goiânia (GO); Borba, Vargas e Wizniewsky (2012) Promovendo a Educação Ambiental e a sustentabilidade através da prática da agricultura de base ecológica; Costa, Souza e Pereira (2015) horta escolar: Alternativa para promover Educação Ambiental e desenvolvimento sustentável no Cariri Paraibano. Ações como essas, além de promover o ensino em prol da Educação Ambiental, conforme foi comentado anteriormente, favorecem transformações de espaços escolares inaproveitáveis em ambientes propícios à construção do saber, pois o espaço físico também contribui para inspirar inovações no dia a dia da escola (LOPES, 2016). Agricultura urbana como prática alternativa para educação ambiental: uma proposta de sistematização e ações em São Luís (MA), Linhares et al. (2018), trata desse tema.

\section{Metodologia}

\section{Tipo de estudo}

A pesquisa consistiu numa forma de desenvolvimento de intervenção de caráter pedagógico. Apesar de o termo intervenção pedagógica parecer estranho para muitos pesquisadores, Damiani et al. (2013) apresentaram uma boa fundamentação teórica para que o mesmo pudesse ser utilizado. Segundo o mesmo autor, as intervenções pedagógicas consistem em investigações envolvendo o planejamento e a implementação de interferências (mudanças, inovações) - destinadas a produzir avanços e melhorias nos processos de aprendizagem daqueles que delas participam. As pesquisas do tipo intervenção pedagógica são aplicadas com a finalidade contribuir para a solução de problemas práticos. Elas se opõem às pesquisas básicas, que objetivam ampliar conhecimentos, sem a preocupação com seus possíveis benefícios práticos (DAMIANI et al., 2013, apud GIL, 2010). Além disso, os mesmos autores explicam que após tal intervenção, ocorre uma posterior avaliação dos efeitos dessas interferências. Diante do exposto, tentou-se desenvolver por meio do presente trabalho de pesquisa, uma forma de intervenção pedagógica com alunos do Centro de Ensino Integral Aquiles Batista Vieira, da cidade de Alcântara - MA, inserindo-os no contexto do preservacionismo e em práticas voltadas ao desenvolvimento sustentável. Para isso, a ação ocorreu pela implantação de uma horta escolar, através da realização de uma Disciplina Eletiva ministrada na citada escola, onde os educandos puderam aprender os princípios fundamentais da sustentabilidade, por meio de aulas teóricas e práticas.

\section{Fases}

Para a aplicação, este projeto inicialmente teve que ser apresentado à direção da escola e depois aos alunos, por meio do "Feirão das Eletivas", logo após foi feita uma seleção das turmas, realização das aulas teóricas e práticas e por último a culminância das disciplinas eletivas.

revista brasileira educação ambiental 


\section{Critério de inclusão na disciplina eletiva}

Conforme já foi explicitado, a horta escolar foi desenvolvida por meio de uma única disciplina denominada "Educação Ambiental na Horta escolar", que foi ofertada semestralmente juntamente com mais seis disciplinas eletivas como parte do currículo da escola de tempo integral, totalizando sete, por haver o mesmo número de turmas na instituição. Na grade curricular das escolas de tempo integral, do estado do Maranhão em 2017, foram ofertadas 80 horas de disciplinas eletivas, onde o educando escolhia uma de acordo com seu interesse. Nesse sistema de ensino, são disponibilizadas 40 (quarenta) vagas em cada eletiva.

No início de cada semestre, os professores elaboraram um "Cardápio" de 7 (sete) disciplinas eletivas a serem escolhidas livremente pelos alunos por meio do "Feirão das Eletivas", onde cada uma teve um nome chamativo para despertar o interesse dos alunos e os professores responsáveis por ministrar as mesmas fizeram propaganda para atrair o máximo de alunos possíveis e fecharem as vagas disponíveis. Dessa forma, numa mesma turma de eletiva existiram alunos de todas as turmas da escola, ou seja, 40 alunos da faixa etária de 15 a 17 anos.

No desenrolar desta disciplina eletiva, o professor de Biologia (coordenador da mesma) também teve o auxílio de mais três professores em algumas aulas, um de Geografia, uma de Biologia e um de Química, que apresentaram a interdisciplinaridade inerente à Educação Ambiental. Tal disciplina durou de 01 de agosto de 2017 a 15 de janeiro de 2018. É importante salientar que tais eletivas oferecidas na escola, não reprovam, mas ajudam com notas de 0 (zero) a 5 (cinco) pontos em todas as disciplinas em cada bimestre.

\section{Realização das aulas teóricas e práticas}

Após a inclusão dos alunos que optaram pela eletiva, ocorreram as aulas teóricas e práticas ministradas semanalmente na escola, com os seguintes conteúdos programáticos:

- Vegetais: Utilização dos vegetais para satisfazer as necessidades do homem: cultivo, plantações, extrativismo, etc. e como isso afeta o meio ambiente;

- Vegetais mais consumidos no Brasil e em Alcântara - MA:

- Botânica: taxonomia e morfologia vegetal, metabolismo energético;

- Tempo necessário para produção de cada hortaliça;

- Período adequado para produção de hortaliças;

- Micro e Macro nutrientes vegetais; 
- Hidroponia como uma alternativa de cultivo de hortaliças (visita técnica a um cultivo de hortaliças por meio da hidroponia).

- Solo e ecossistema: importância do solo para os seres vivos, identificando seus tipos, processos de formação e utilização pelo homem.

- Construção da horta escolar:

- Desenvolvimento sustentável e práticas;

- Ecossistema e ação antrópica;

-Solos: manejo adequado, fertilização e correção.

-Compostagem

- Saúde do ambiente: erosão e importância da preservação das matas ciliares; modificações que ocorrem no ambiente, identificando os agentes causadores, as consequências e a intervenção humana (Durante essa aula ocorreu uma visita técnica ao Rio Pepital, que abastece a cidade de Alcântara - MA).

\section{Culminância das eletivas}

A finalização da eletiva ocorre num momento que se chama "Culminância". É um dia, no final do semestre, no qual a escola se prepara para expor para toda a comunidade escolar o que foi produzido, em clima de compartilhamento de conhecimentos, de experiências, de aprendizado e de proposições de desafios para avançar nos próximos períodos.

Nesta ocasião, além de apresentarem o resultado do desenvolvimento da horta e dos vegetais que foram cultivados, os discentes tiveram a oportunidade de falar sobre o que aprenderam: as bases acadêmicas, as escolhas que fizeram e os valores que consolidaram. Para isto, os alunos da turma foram divididos em três grupos que se apresentaram por meio de stands, demonstrando apenas um pequeno resumo do que fora trabalhado na disciplina. Ressalta-se que essas apresentações tiveram que ser breves, pelo fato de que além desta disciplina eletiva, ainda havia mais sete outras eletivas que precisavam apresentar o que se produziu ao longo do período letivo.

\section{Resultados e discussões}

\section{Desenvolvimento e construção da horta escolar}

As áreas subutilizadas da escola foram tratadas e ganharam uma nova vida através da implantação da horta como forma de conscientização e prática educativa em prol da sustentabilidade ambiental. Isso ocorreu ao longo de todo o segundo semestre de 2017, onde se puderam notar transformações de espaços escolares antes aproveitados, e agora como espaços de construção de conhecimento totalmente revitalizados pelos próprios educandos (Figura 1 e 2). 


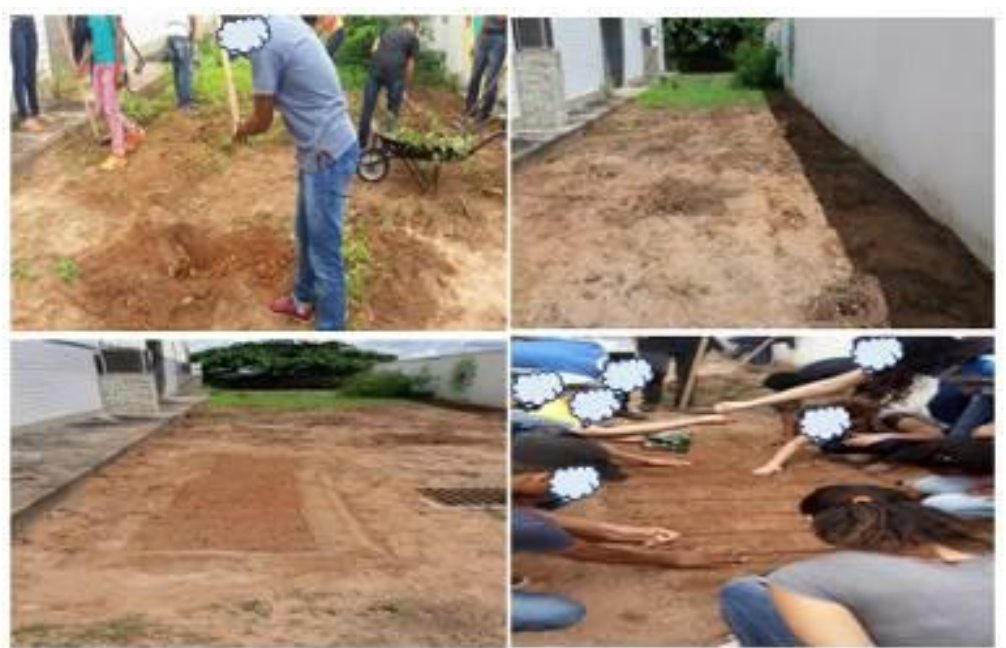

Figura 1: Prancha de imagens mostrando a preparação do terreno para implantação da horta escolar no Centro de Ensino Integral Aquiles Batista Vieira, Alcântara - MA.

Fonte: Autor, agosto de 2017.

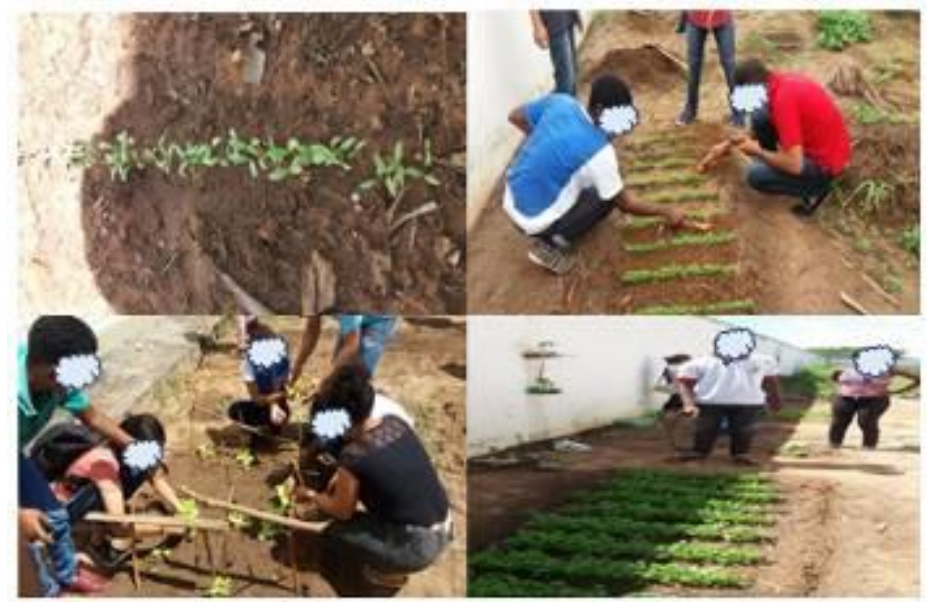

Figura 2: Crescimento dos primeiros cultivos da horta escolar no Centro de Ensino Integral Aquiles Batista Vieira, Alcântara - MA, agosto de 2017. Fonte: Autor, setembro de 2017.

Inicialmente, os alunos apresentaram-se meio relutantes para trabalhar em prol da limpeza do espaço de implantação da horta, pois a princípio foi cansativo tanto para o professor quanto para eles. Mas a perseverança dos mesmos foi sendo alimentada pelo desejo de adquirir a pontuação que a disciplina eletiva forneceria no fim de cada bimestre e posteriormente, começaram a ser recompensados com o crescimento da vegetação e a consequente ornamentação que as mesmas puderam trazer. Dessa forma, perceberam que haviam se tornado agentes efetivos de uma ação ambiental enriquecedora de conhecimentos que transforma tanto o físico quanto 0 intelectual.

Essa forma de intervenção pedagógica gerou resultados relevantes nos educandos, por isso, de acordo com Damiani et al. (2013), deve-se avaliar o que a mesma pode trazer de positivo para o educando. Por esse motivo, 
alguns alunos foram perguntados a respeito do modo como a forma de intervenção contribuiu para a aprendizagem sobre Educação Ambiental. Dentre algumas falas dos alunos, pode-se destacar algumas como:

Trabalhar com a horta escolar me ajudou a entender alguns nomes estranhos que o professor usava na aula teórica, como a palavra sustentabilidade. Ele sempre dizia que isso significava que aquilo que a gente tem hoje, pode ser preservado para as gerações futuras. Fazer essa horta me ajudou a entender que se eu não cuidar dela, os próximos alunos dessa escola não poderão desfrutar dela (Aluna da Turma do $2^{\circ}$ Ano B).

Pra falar a verdade, quando eu fui escolher a minha eletiva "Educação ambiental" esteve em $3^{\circ}$ plano. E quando caiu "Educação ambiental" eu ainda pensei em trocar. No nosso primeiro dia de eletiva, a pergunta: "Pra você, o que é Educação Ambiental?" E eu sinceramente discordo do que eu coloquei naquele papel (em partes). A Educação

Ambiental não é só pra te ajudar a lembrar de por um saco no lixo, (por mais que seja uma ajuda e tanto pro nosso meio ambiente). Educação ambiental, é sobre esperar; sobre dar a receber. Esperar o tempo para plantar, colher e com certeza ter a sua recompensa final! Dar e receber: é o cuidado com a terra, ou até mesmo com o sistema hidropônico. Com a educação ambiental eu não aprendi a somente cuidar e plantar, eu aprendi a conviver, a pensar no mundo e a querer preservar esse verde bonito para que, quem sabe, outra geração possa ver! Para tudo há um esforço, braçal e também mental. E isso nos ajuda de maneira sustentável, política e até mesmo economicamente. Educação ambiental é cuidar de tudo o que está a volta, e se conscientizar de que um dia isso pode acabar pelas nossas mãos. Porque não fazer parte de uma pequena porcentagem que se preocupa com isso? (Depoimento de uma aluna da turma do $2^{\circ}$ Ano $A$ ).

De acordo com o exposto nas falas acima, percebe-se que as aulas teóricas e práticas promovidas pela disciplina eletiva de Educação Ambiental promoveram nos alunos o processo de conscientização, constatando-se assim que a disciplina alcançou seus objetivos e, além disso, que motivou ainda mais o desenvolvimento de práticas que corroboram o crescimento intelectual de cidadãos comprometidos com o futuro do planeta.

Aulas práticas são essenciais ao desenvolvimento de qualquer conhecimento, inclusive à Educação Ambiental, como foi neste caso. A função básica e essencial das aulas é despertar o interesse e a curiosidade dos alunos para o aprendizado (ROCHA; BEZERRA, 2013). Segundo os mesmos autores, 
as atividades práticas associadas à teoria desperta o interesse nos discentes em refazê-las e analisá-las, relacionando-as ao cotidiano de cada um.

Além disso, os vegetais cultivados na horta puderam ser usados pelo pessoal da cozinha na preparação da alimentação servida na escola, como: a melancia (Citrullus lanatus); Coentro (Coriandrum sativum); Pepino (Cucumis sativus), Alface (Lactuca sativa) (Figura 3 de A até D) e no fornecimento de remédios naturais, uma vez que também se utilizou deste espaço como cultivo de ervas medicinais (Figuras 3.E).

Essa iniciativa tem sido desenvolvida em várias instituições. O Site G1, por exemplo, apresentou uma reportagem, em 06 de outubro de 2017, a respeito do desenvolvimento de um projeto intitulado "Horta Sustentável" por uma escola de Santarém, oeste do Pará, onde as plantas cultivadas puderam ser utilizadas na merenda escolar (CADETE, 2017). Os professores podem usar a interdisciplinaridade e desenvolver projetos sobre alimentação saudável, pois os alunos terão a oportunidade de conhecer melhor os alimentos e experimentá-los na cozinha ou na merenda escolar, o que os auxiliará na promoção da saúde.
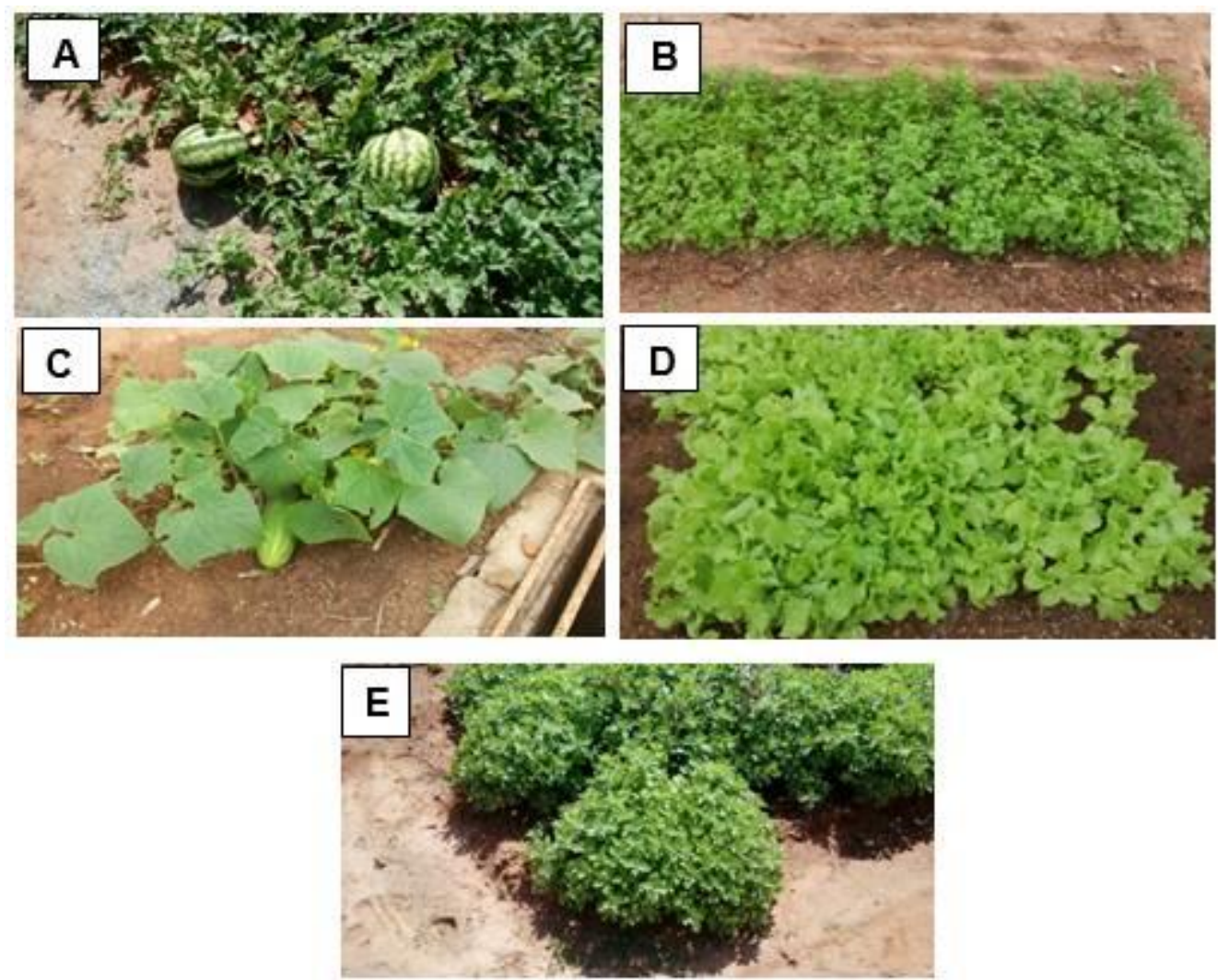

Figura 3: Produção cultivada na horta com destaque para A - Melância (Citrullus lanatus); B Coentro - (Coriandrum sativum); C - Pepino (Cucumis sativus); D - Alface (Lactuca sativa); E Ervas medicinais como o boldo-do-chile (Peumus boldus).

Fonte: Autores, dezembro de 2017 


\section{Compostagem}

De acordo com Oliveira, Sartori e Garcez (2008), a compostagem é o processo biológico de decomposição e de reciclagem da matéria orgânica contida em restos de origem animal ou vegetal formando um composto. A compostagem propicia um destino útil para os resíduos orgânicos, evitando sua acumulação em aterros, melhorando a estrutura dos solos e, portanto, é uma boa prática de sustentabilidade a ser ensinada por essa disciplina de Educação Ambiental.

Por ser a escola de tempo integral, os alunos precisam almoçar lá mesmo. Como consequência, muita comida estava sobrando e acabava sendo desperdiçada. Para sanar este problema, aproveitou-se a realização da eletiva de Educação Ambiental na horta escolar para que os alunos tivessem aulas sobre esse processo de aproveitamento. Durante as aulas teóricas foi mostrado aos alunos como é feita a compostagem e, após isso, os próprios alunos tiveram a oportunidade de construir uma composteira (Figura 4. A e B) para aproveitar os restos alimentares e fabricar adubo natural para posterior utilização na mini-horta escolar (Figura 4. C).
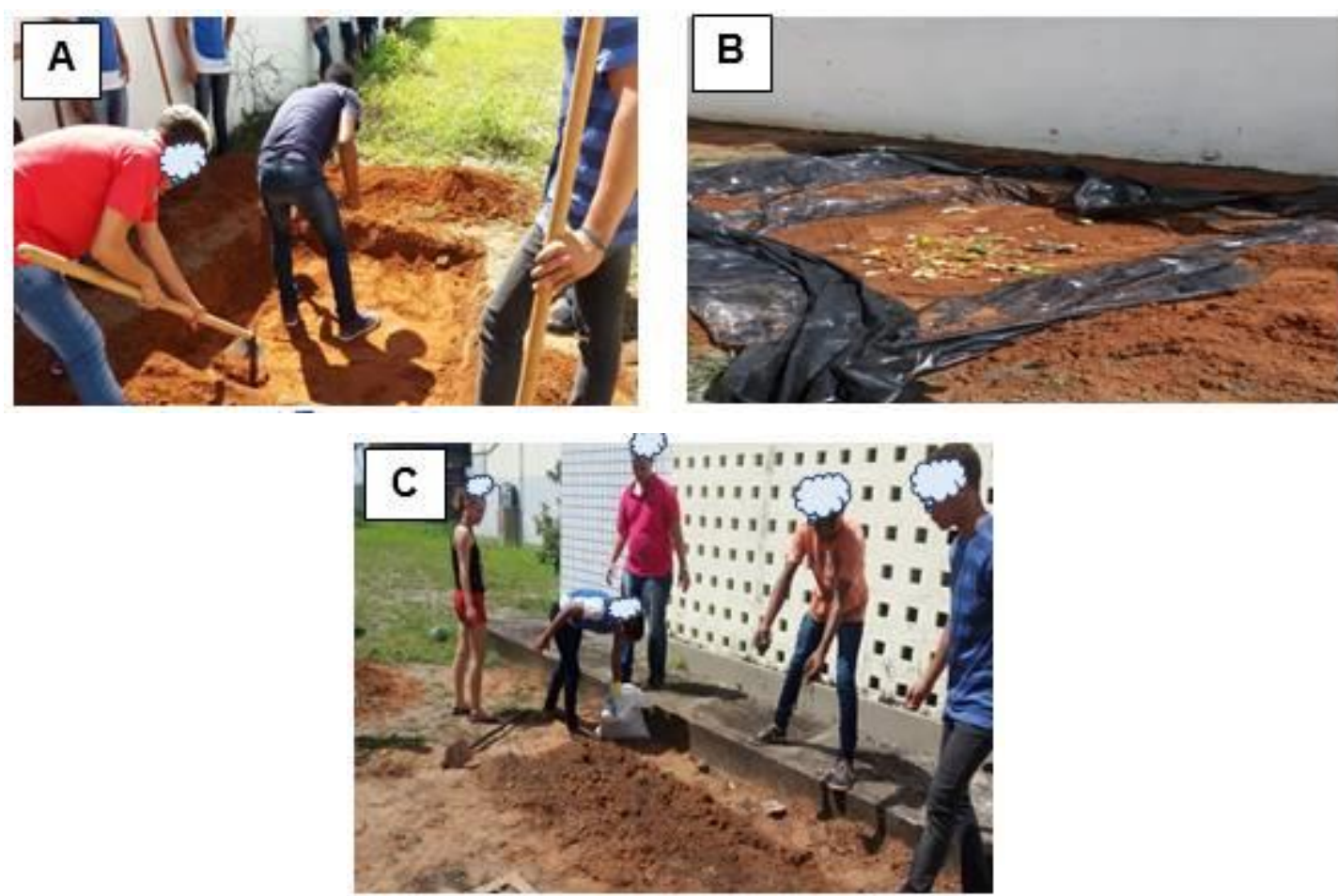

Figura 4: Prancha do Desenvolvimento da Compostagem durante as aulas práticas imagens $A$ e B. Produção da composteira C. Fonte: Autores, 2017.

Sobre essa prática, os discentes puderam compreender o tamanho do valor que a comida desperdiçada pode apresentar para o cultivo dos vegetais, pois alguns confessaram que não imaginavam que se poderia dar um destino adequado para alimentos desperdiçados e, além disso, entenderam que se deve evitar o desperdício ao máximo.

Revbea, São Paulo, V. 13, № 4: 228-247, 2018.

revista brasileira educação ambiental 


\section{Horta Escolar para compreender a origem antrópica dos Impactos Ambientais}

Outra grande utilidade da horta escolar é poder ser usada para compreender quanto o homem pode contribuir para o aumento dos impactos ambientais negativos. Durante as aulas teóricas e na culminância dessa disciplina, pôde ser visto mais adiante que foi trabalhada a temática do processo erosivo, inversão térmica, assoreamento dos rios com impactos ambientais negativos influenciados pelo homem.

Segundo a resolução Conama №001 de janeiro de 1986, o impacto ambiental é definido como:

Qualquer alteração das propriedades físicas, químicas e biológicas do meio ambiente, causada por qualquer forma de matéria ou energia resultante das atividades humanas que, direta ou indiretamente, afetam a saúde, a segurança e o bemestar da população; as atividades sociais e econômicas; a biota; as condições estéticas e sanitárias do meio ambiente; e a qualidade dos recursos ambientais (BRASIL, 1986).

Entende-se que a Educação Ambiental pode mudar esses hábitos, transformar a situação do planeta Terra e proporcionar uma melhor qualidade de vida para as pessoas. E isso só se fará com uma prática de educação ambiental, onde cada indivíduo se sinta responsável em fazer algo para conter o avanço da degradação ambiental (MEDEIROS et. al., 2011). Na fala de alguns dos educandos, ouviu-se que "as aulas ministradas por meio dessa disciplina ajudaram a entender os conteúdos de maneira mais visível". Isso comprova o que Piaget (1967) fala sobre as constantes associações cognitivas ou inter-relações do que os sentidos dos educandos se apropriam, com a ideia racional ou inteligível resultante dessas interações com o mundo em sua volta.

\section{Culminância das disciplinas eletivas}

Ao término do segundo semestre letivo de 2017 (janeiro de 2018), ocorreu uma culminância do projeto das disciplinas eletivas do Centro de Ensino em Tempo Integral Aquiles Batista Vieira. Na disciplina de Educação Ambiental, na horta escolar, os educandos apresentaram toda a sua produção por meio de stands onde puderam resumir alguns temas abordados nas aulas práticas e teóricas da disciplina, como: Hidroponia como técnica sustentável de cultivo (Figura 5) e apresentação da horta escolar para a comunidade (Figura $6)$. 

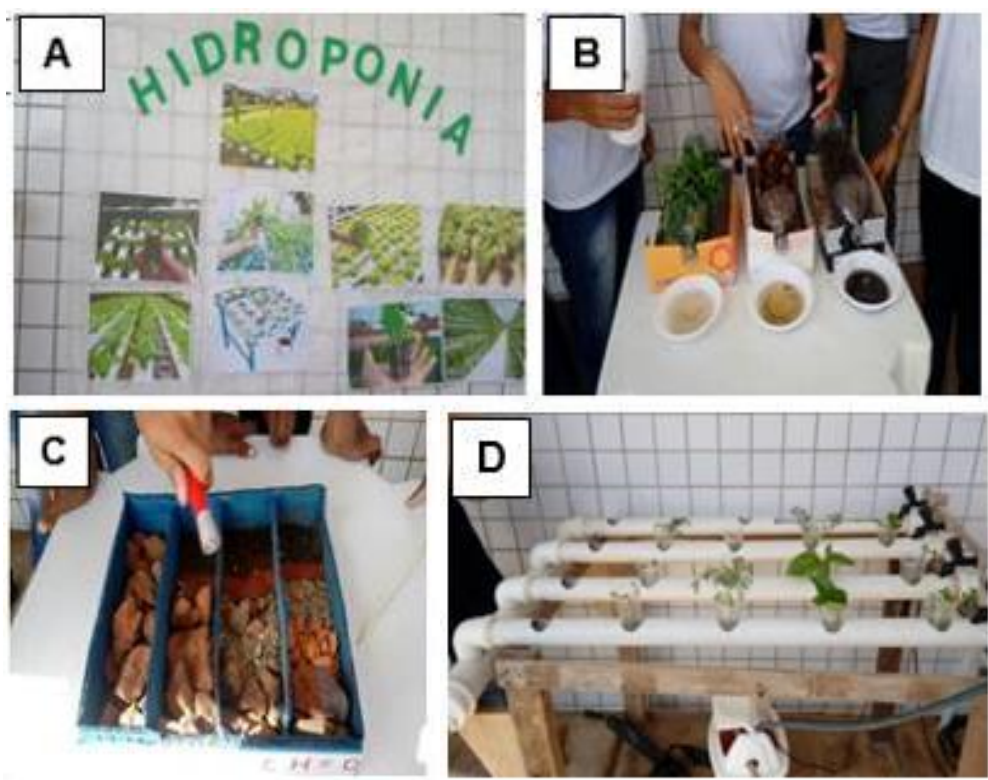

Figura 5: Mosaico Stands de apresentação na Culminância do Projeto da Disciplina Eletiva de Educação Ambiental na horta Escolar. A: Hidroponia como técnica sustentável de cultivo; B: importância da mata ciliar para a diminuição do assoreamento; C: formação do solo demonstrado a partir de uma maquete. Fonte: Autor, janeiro de 2018.

\section{Hidroponia como técnica sustentável de cultivo}

Durante a culminância da disciplina de Educação Ambiental na horta escolar, os alunos puderam utilizar um pequeno sistema de hidroponia que foi fornecido por um morador que reside nas proximidades da escola, para mostrálo como técnica sustentável de cultivo de hortaliças a toda comunidade escolar. Isso foi possível porque durante as aulas teóricas ocorreram visitas técnicas a pessoas que cultivam hortaliças em suas casas. Dessa forma, os educandos puderam aprender o mecanismo básico de funcionamento de um sistema hidropônico e explicá-lo durante a culminância em um dos stands.

O cultivo hidropônico é uma forma de produção agrícola com uso de solução nutritiva em ambiente protegido, apresenta ótima produtividade por área e alta qualidade dos alimentos (MENEGAES et. al., 2015). Essa técnica de cultivo pode ser considerada sustentável, pois de acordo com o mesmo autor, fornece o mínimo desperdício de água e nutrientes e além do mais, não necessita de grandes áreas de plantio. Pôde-se observar que na fala de várias pessoas da comunidade escolar, havia muito entusiasmo e o desejo de fazer algo parecido em suas casas. Isso mostra quanto projetos como esse podem ser influenciadores de ações efetivas em meio à sociedade.

\section{A importância da mata ciliar para a diminuição do assoreamento}

Durante a execução da disciplina de Educação Ambiental, os alunos também tiveram uma oportunidade de visitar o rio Pepital (Figuras 6 e 7), principal fonte de abastecimento de água da cidade de Alcântara - MA, para 
que se pudesse explicar o que é e qual a importância das matas ripárias (Figura 7).

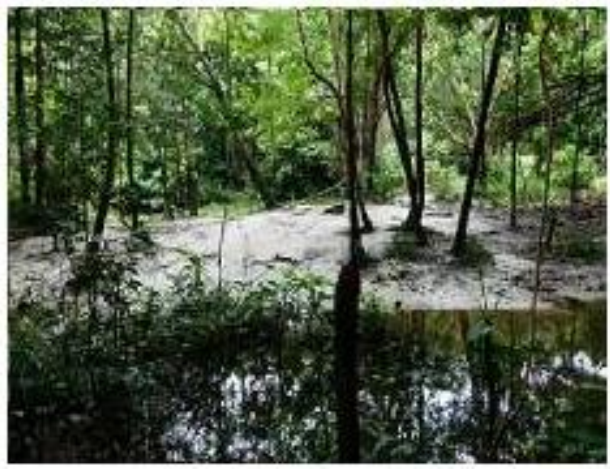

Figura 6: Rio Pepital, Alcântara - MA Fonte: Google Imagens, 2018.

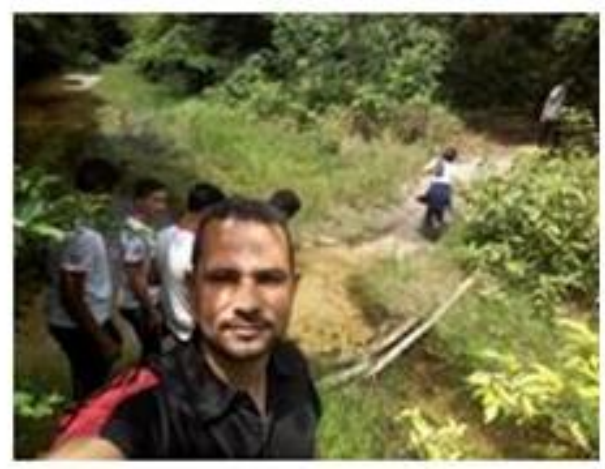

Figura 7: Visita para a realização da aula de campo sobre preservação da mata ciliar.

Fonte: Autor, setembro de 2017.

Entende-se por vegetação ciliar ou ripária, aquela que margeia as nascentes e os cursos de água (CHAVES, 2009). O mesmo autor ainda afirma que essa vegetação é fundamental para a preservação ambiental especialmente para a manutenção das fontes de água e da biodiversidade. Por ser um assunto de extrema importância, não se poderia deixar de abordá-lo e dessa forma, entendeu-se que essa seria a melhor a melhor maneira de introduzir o conteúdo.

Durante essa aula, os educandos puderam compreender a importância da mata ciliar para a diminuição do assoreamento dos rios. Isso pôde ser constatado através da apresentação em um dos stands (Figura 5. B), onde foram simulados três ambientes: Um coberto por vegetação, outro com folhagem seca e um último sem cobertura vegetal. Ao jogar água em cada ambiente (simulando água da chuva), recolhiam a água que escorria e assim demonstravam que a amostra que mais continha sedimentos carreados, era o que não continha cobertura vegetal. Dessa forma ao se promover essa visita e realizar essa simulação, o termo mata ciliar ou ripária e a sua importância puderam se tornar mais inteligíveis e compreensíveis do que em aulas tradicionais. Notou-se que as explicações desenvolvidas pelos alunos durante as suas apresentações, sofreram influência da própria visita feita ao Pepital anteriormente relatada, pois durante suas abordagens, elucidaram quanto é importante a preservação do rio de sua cidade com a diminuição do processo de assoreamento.

\section{Formação do solo}

O solo é um componente fundamental do ecossistema terrestre, pois é o principal substrato utilizado pelas plantas para o seu crescimento e disseminação. $O$ solo fornece às raízes fatores de crescimento como suporte, água, oxigênio e nutrientes (LIMA; LIMA e MELO, 2007). Descrever os tipos de solos mais apropriados para o cultivo de determinados produtos e aplicar Revbea, São Paulo, V. 13, № 4: 228-247, 2018. 
técnicas de manejo do solo para um melhor cultivo de hortaliças é de extrema importância para se promover o cultivo com o máximo de sustentabilidade possível. Mas para que isso aconteça, é necessário entender o processo de formação do mesmo. O estudo científico do solo, a aquisição e a disseminação de informações sobre o papel que o mesmo exerce, e sua importância na vida do homem são condições primordiais para sua proteção e conservação, e a garantia da manutenção de um ambiente sadio e sustentável (LIMA; LIMA e MELO, 2007). Diante do exposto, durante a culminância, os alunos também realizaram por meio de um stand, uma maquete de formação do solo (Figura 3. C), explicaram à comunidade escolar por meio do mesmo, o que aprenderam na teoria e na prática a respeito das fases e os horizontes (camadas) que formam o solo, demonstrando para a comunidade a importância de se promover a aeração do solo e sua correção por meio de fertilizantes naturais.

\section{Apresentação da horta escolar para a comunidade}

Durante a culminância foi apresentado o resultado do desenvolvimento da horta escolar e seus vegetais produzidos após um semestre de trabalho. $\mathrm{Na}$ ocasião, ocorreu a visita de uma técnica da Unidade Regional de Educação (URE). A presença dessa representante foi muito importante, pois o projeto pôde ser estendido às demais escolas da região e, assim pôde-se dar início a uma rede de sustentabilidade escolar e ao mesmo tempo conscientizar mais pessoas sobre os benefícios das hortas escolares. É salutar destacar que a participação da comunidade extraescolar é de suma importância para o sucesso do projeto (Figura 8).

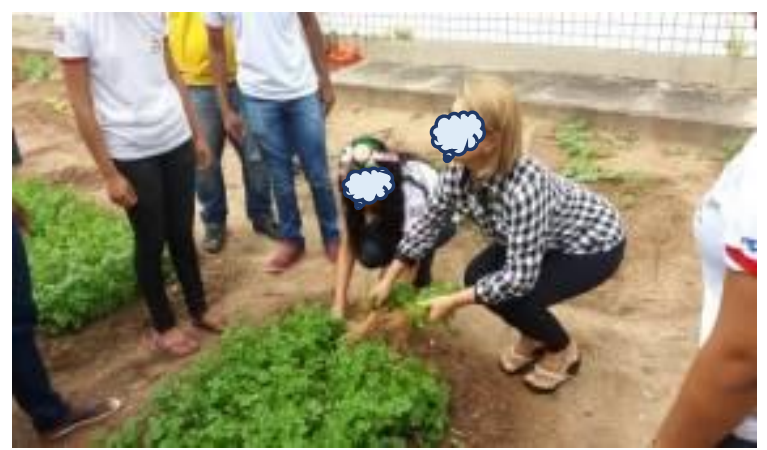

Figura 8: Apresentação da horta à comunidade escolar visita de uma técnica da URE.

Fonte: Autor, janeiro de 2018.

Souza e Pereira (2015) advogam que a horta escolar é uma ferramenta primordial para o desenvolvimento de cidadãos competentes para a promoção da sustentabilidade e por isso, projetos como esse, incentivam a comunidade a desenvolvê-lo no sentido de, além de poderem obter renda extra com a venda dos produtos, promoverem uma forma de desenvolvimento sustentável. Isso é tão possível que, ao serem indagados sobre a contribuição dessa disciplina para a sua formação como cidadãos, alguns alunos responderam que os ensinamentos aprendidos no desenvolvimento da horta escolar proporcionaram 
a possibilidade de os mesmos cultivarem alimentos em suas casas ou até mesmo de poderem vender e ganhar uma renda extra para a família.

É necessário ressaltar que este projeto, uma vez implantado na escola, deverá ser mantido como laboratório vivo importante para a integração curricular, além disso, conforme foi comentado anteriormente, a horta escolar é uma importante ferramenta para se promoverem assuntos ligados à alimentação saudável e à segurança alimentar. Isso será possível pelo fato de que a gestão escolar do Centro de Ensino em Tempo Integral Aquiles Batista Vieira deixou claro que será dedicado um pequeno recurso da alimentação escolar (fornecido pela SEDUC-MA) para se comprarem alguns insumos agrícolas tais como: sementes e ferramentas, além de buscarem parcerias com criadores de gado da vizinhança para fornecimento de esterco. Nesse sentido, esse projeto, além de proporcionar aprendizado aos educandos, continuará sendo de suma importância econômica para a escola.

\section{Considerações Finais}

A aplicação deste projeto consistiu em mostrar para a comunidade escolar os benefícios proporcionados pela horta escolar, no que diz respeito assimilação de conhecimentos relativos à preservação do meio ambiente, cultivo sustentável de hortaliças, problemas ambientais e aplicação da teoria relacionada a boas práticas ambientais através do desenvolvimento da horta escolar.

Cada aula vivenciada foi uma maneira intencional de fazer os estudantes esforçarem-se para a construção de um espaço de convivência e de aprendizagem de conceitos essenciais à sua sensibilização ambiental, que os levou a uma maior valorização em manter e cuidar do mesmo. Essa experiência trouxe aos educandos contexto mais amplo dos conhecimentos teóricos abordados em sala de aula, uma vez que puderam colocar em prática - que Almeida (2003) chama de sensibilizar pela construção e pela manipulação de materiais com as mãos, pelos movimentos do corpo e pelo despertar das sensações.

Destacou-se ainda o instrumento da horta escolar como uma ferramenta da Educação Ambiental, servindo não apenas como uma simples forma de cultivo de hortaliças, mas também como um laboratório de aprendizagem de conhecimentos tão específicos que simples aulas teóricas não seriam suficientes para a aprendizagem dos educandos.

Além da teoria associada à prática com a horta escolar, notou-se que utilizando a culminância do projeto das disciplinas eletivas, os educandos puderam, por meio de suas apresentações com stands, colocar em prática o que aprenderam durante o tempo em que estiveram participando da eletiva e assim compartilhar conhecimentos vivenciados na prática, o que tornou a aprendizagem cada vez mais significativa. 
Em uma visão mais crítica e especializada de quem vem trabalhando há algum tempo na área de educação, esse foi um dos projetos que, ao ser analisado, tratou do um ensino de Educação Ambiental com uma visão mais holística, pois trabalhou as habilidades cognitivas dos educandos, aliou a teoria com a prática e ainda transformou o espaço escolar. Cada vez mais que educadores lançarem mão de práticas como essa, bons cidadãos serão formados, ambientes escolares serão transformados e comunidades escolares poderão ser efetivamente sensibilizadas ambientalmente. Portanto, aconselhase que iniciativas como essas possam ser utilizadas e implantadas no máximo de instituições possíveis, a fim de que se promova uma conscientização ambiental cada vez mais efetiva.

\section{Referências}

ALMEIDA, P.N. O educador e o Lúdico. In: Educação Lúdica: Técnicas e

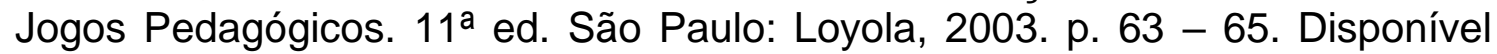
em: $\quad<$ http://books.googlole.com.br/books?id=-fzErzs9UkwC\&printsec=front cover\#v=onepage\&q\&f=false $>$. Acesso em 11 de Jun. 2017.

BORBA, S.N.S; VARGAS, D.L; WIZNIEWSKY, J.G. Promovendo a Educação Ambiental e sustentabilidade através da prática da agricultura de base ecológica. In: I Congresso Internacional de Direito Ambiental e Ecologia Política e III Seminário de Ecologia Política e Direito na América Latina. Rio Grande do Sul. Anais. Rio Grande do Sul: UFSM, 2012, p. 631 - 639.

BRASIL, Ministério do Meio Ambiente. Resolução Conama n 001, de 1986, LICENCIAMENTO AMBIENTAL - Normas e procedimentos, Brasília, DF. 1986.

BRASIL. Ministério da Educação. Educação Ambiental: aprendizes de sustentabilidade. Brasília, DF, 2007. 108 p. Disponível em: $<$ http://portal.mec.gov.br/dmdocuments/publicaca02.pdf>. Acesso em 03 de Mar. 2018.

BRASIL. Parâmetros Curriculares Nacionais: apresentação dos temas transversais. Parâmetros curriculares nacionais: meio ambiente e saúde. Secretaria de Educação Fundamental. Brasília: MEC/SEF, 1997.

CADETE, F. Horta Sustentável' incentiva o cultivo de verduras e legumes em escola de Santarém. 2017. Disponível em: <https://g1.globo.com/pa/s antarem-regiao/noticia/horta-sustentavel-incentiva-o-cultivo-de-verduras-elegumes-em-escola-de-santarem.ghtml>. Acesso em: 23 fev. 2018.

CHAVES, A. Importância da mata ciliar (legislação) na proteção dos cursos hídricos, alternativas para sua viabilização em pequenas propriedades rurais. Seminário apresentado na disciplina "manejo e conservação do solo e da água"- Universidade de Passo Fundo, 2009.

CHIAVENATO, J. J. O massacre da Natureza. São Paulo: Moderna, 2005. 
COELHO, D.E.P.; BÓGUS, C.M. Vivências de plantar e comer: a horta escolar como prática educativa, sob a perspectiva dos educadores. Saúde Sociedade. São Paulo, v.25, n.3, p.761-771, 2016.

COSTA, C.A.G; SOUZA, J.T.A; PEREIRA, D.D. Horta escolar: Alternativa para promover Educação Ambiental e desenvolvimento sustentável no Cariri Paraibano. Polêmica. Rio de Janeiro. v. 5, n. 3. 2015. Disponível em: < http://www.e-publicacoes.uerj.br/index.php/polemica/article/view/19350>.

Acesso em: 18 Fev. 2018.

DAMIANI, M.F.; ROCHEFORT, R.S.; CASTRO, R.F.; DARIZ, M. R.; PINHEIRO, S. S. Discutindo pesquisas do tipo intervenção pedagógica. Cadernos de Educação. Pelotas, RS, n. 45, 2013, p. 57 - 67.

ENO, E.J.; LUNA, R.; LIMA, R.A. Horta na escola: incentivo ao cultivo e a interação com o meio ambiente. Revista Eletrônica em Gestão, Educação e Tecnologia Ambiental Santa Maria, v. 19, n. 1, jan.-abr. 2015, p. 248-253.

FOLADORI, G. O capitalismo e a crise ambiental. Disponível em: $<$ http://www.egov.ufsc.br/portal/conteudo/o-capitalismo-e-crise-ambientall>.

Acesso em 11 de junho de 2017.

GIL, A.C. Como Elaborar Projetos de Pesquisa. 5a. Ed. São Paulo: Atlas, 2010, 184p.

JACOBI, P. Educação ambiental, cidadania e sustentabilidade. Cadernos de Pesquisa, n. 118, março/ 2003 Cadernos de Pesquisa, n. 118, p. 189-205, março. 2003.

LIMA, V.C.; LIMA, M.R.; MELO, V.F. (Eds.). O solo no meio ambiente: abordagem para professores do ensino fundamental e médio e alunos do ensino médio. Curitiba: Universidade Federal do Paraná, Departamento de Solos e Engenharia Agrícola, 2007. 130 p.

LINHARES, J.F.P.; ROJAS, M.O.A.I.; RODRIGUES, M.I.A. Agricultura urbana como prática alternativa para educação ambiental: uma proposta de sistematização e ações em São Luís (MA). Revbea, São Paulo, V. 13, No 1: 10-21, 2018.

LOPES, M. Projeto transforma o ambiente escolar com a participação da comunidade. Por Vir. 9 de ago. de 2016. Disponível em: <http://porvir. org/projeto-transforma-ambiente-escolar-participacao-da-comunidade/>.

Acesso em: 22 fev. 2018.

MEDEIROS, A.B.; MENDONÇA, M.J.S.L.; SOUSA, G.L.; OLIVEIRA, I. A Importância da educação ambiental na escola nas séries iniciais. Revista Faculdade Montes Belos, v. 4, n. 1, set. 2011. Disponível em: <http://www. terrabrasilis.org.br/ecotecadigital/pdf/a-importancia-da-educacao-ambiental-naescola-nas-series-iniciais.pdf. >. Acesso em: 24 fev. 2018.

MELLO, M.A. A atividade mediadora nos processos colaborativos de educação continuada de professores: educação infantil e educação física. 2001. Tese (Doutorado em Educação) - Centro de Educação e Ciências Humanas, Universidade Federal de São Carlos, São Carlos.

Revbea, São Paulo, V. 13, № 4: 228-247, 2018. 
MELLO, M.A. A intencionalidade do movimento no desenvolvimento da motricidade infantil. Multiciência. ASSER: São Carlos, vol.1, no 1, nov.1996.

MENEGAES, J.F.; FILIPETTO, J.E.; RODRIGUES, A.M; SANTOS, O. Produção sustentável de alimentos em cultivo hidropônico. Revista Monografias Ambientais. Santa Maria, v. 14, n. 3, Set-Dez. 2015, p. 102-108. MINC. C. Ecologia e Cidadania. 2ed, São Paulo: Moderna, 2005.

NUNES MOURA, H. Jogo didático sobre conceitos bioquímicos: produção, aplicação e avaliação. Trabalho de conclusão de curso - UFPI - Campus Ministro Petrônio Portela, Teresina, 2011. p. 53.

OLIVEIRA, E.C.A.; SARTORI, R.; GARCEZ, T.B. Compostagem. Seminário (Matéria Orgânica do Solo) - Universidade de São Paulo, 2008.

PIAGET, J. Seis estudos de psicologia. Cia Editora Forense. 1967

PIMENTA, J.C.; RODRIGUES, K.S.M. Projeto Horta Escolar: Ações de Educação Ambiental na escola Centro Promocional todos os Santos de Goiânia (GO). In: II Simpósio de Educação Ambiental e transdisciplinaridade. 2011, Goiânia. Anais... Goiânia: UFG/IESA/NUPEAT, p. 1-11.

PINHEIRO, H.B.; PAULA, A.P.V.B.; PESSOA, C.A.N. A construção de hortas coletivas escolar como prática transdisciplinar de sustentabilidade planetária. In: Conferência Internacional Saberes para uma Cidadania Planetária, 2016, Fortaleza-CE. Anais... Fortaleza: UECE, 2016. p. 1 - 12. Disponível em: $<$ http://uece.br/eventos/spcp/anais/trabalhos completos/247-22050-30032016220920.pdf>. Acesso em 04 de Mar. 2018.

QUADROS, A. Educação ambiental: iniciativas populares e cidadania. Monografia (Especialização em Educação Ambiental) - universidade Federal de Santa Maria, 2007. . Disponível em: < http://jararaca.ufsm.br/websites/ unidadedeapoio/download/alessandra.pdf>. Acesso em 03 de Mar. 2018.

QUINTANA, A.C.; HACON, V. O desenvolvimento do capitalismo e a crise ambiental. In: O social em questão. Ano XIV - no 25/26 - 2011.

ROCHA, G.C.; BEZERRA, A.C.S. A importância da prática aliada a teoria no ensino de quimica. In: 11ํ Simpósio Brasileiro de Educação Química, 2013, Teresina/PI. Anais. Rio de Janeiro: Associação Brasileira de Química, 2013.

SANTANA, L.M.S.; MARRUDA, R.; VALMEIDA, L.I.M.; MACIEL, C.M.L. A Horta Escolar como Recurso no Ensino de Ciências na Perspectiva da Aprendizagem Significativa. Revista Ciências Exatas Tecnologia, v. 9, n. 9, p. 37-45, $2014 . \quad$ Disponível em: <http://pgsskroton.com.br/seer/index.php/rcext/article/viewFile/1371/2724>.

Acesso em 03 de Mar. 2018.

SILVA, M.N. A educação ambiental na sociedade atual e sua abordagem no ambiente escolar. Portal de e-governo, inclusão digital e sociedade do conhecimento, 2012.

SIMONETTI, M.C.L., (ORG). A (in) sustentebilidade do desenvolvimento : meio ambiente, agronegócio e movimentos sociais. - São Paulo: Cultura Acadêmica; Marília: Oficina Universitária, 2011. 206 p.

revista brasileira educação ambiental 